\title{
Effects of the Alternative Postharvest Treatments on 'Hicaznar' Pomegranate Fruit Phytochemicals, Organic Acids and Sugar Content
}

\author{
Ayşe Tülin Özi* , Şeyma Hiçyilmaz', Tuğçe Yarşí1 \\ ${ }^{1}$ Department of Food Engineering, Faculty of Engineering, Osmaniye Korkut Ata University, TURKEY
}

\begin{abstract}
Background: There are many alternative techniques have been used for preserving fruits quality and extent shelf life by reducing metabolic activities which promote their quality changes negatively during storage to understand the metabolic process in fresh fruits. Objective: The main objective of this study was to investigate effects of postharvest treatment of gamma-aminobutyric acid (GABA) and oxalic acids (OA) on phytochemicals, organic acid and sugar content of 'Hicaznar' pomegranate fruit. Method: The pomegranate arils were immersed external three different concentrations $(0,2.5$ and $5 \mathrm{mM})$ of $\mathrm{OA}$ and GABA after minimally process of fruit. Total phenolic, anthocyanin, antioxidant activities, organic acid sugar content of treated and control fruit arils were analysed. Results: The present results were indicated that in general, glucose and sucrose sugar contents of fruit slightly decreased at the end of the storage while fructose and sorbitol content slightly increased. Conclusion: OA treated group showed better antiradical activity than GABA treated arils while TAC was higher in GABA treated arils at the end of storage. Total phenolic contents of pomegranate arils were changed significantly during storage.
\end{abstract}

Keywords: Pomegranate Arils, Oxalic Acid, Gamma-Aminobutyric Acid, Sugar, Organic Acid.

\section{INTRODUCTION}

In recent years, marketing of minimally processed fruits and vegetables has increased rapidly. Simply, minimal processing involves of washing, peeling and cutting of fruits and vegetables with suitable treatment to extend shelf-life of fruits and vegetables. ${ }^{1,2}$ There are many alternative new techniques have been used for preserving shelf life fruits by prevent their quality reduction and quantity losses during storage and better understanding to metabolic and the respiration process in fresh fruits through shelf life. Among other applications (controlled or modified atmospheres storage, applying chemical agents, UV and other applications), the treatment of edible coatings is one of the most receptive methods to prolong the commercial shelf-life of fruits. The most important benefits of eco-friendly treatments are; i) it has positive effects on prevent fungal, physiological and biochemical deterioration of fruit; ii) healthy foods as well as to the increasing concerns over the environment in response to the growing demand for safe. ${ }^{3}$ The gamma-aminobutyric acid (GABA) is naturally available in low levels in many plant sources (spinach, potatoes, cabbage, apples, grapes, cereals etc.). GABA is a non-protein amino acid and it is considered as a potent bioactive compound. ${ }^{4}$ Oxalic acid (OA) is one of the organic acid which protect plant from biotic and abiotic negative effects. It has been evaluated that $\mathrm{OA}$ postpone ripening of some climacteric as banana, prevents browning of litchi fruit and banana, increases resistance to chilling injury and extends postharvest shelf life. ${ }^{5}$ There are few studies about OA treatments ${ }^{5-9}$
DOI: 10.5530/ijper.51.3s.65

Correspondence:

Ayşe Tülin Öz,

Department of Food Engineering, Faculty of Engineering, Osmaniye Korkut Ata University, TURKEY

Phone no: +903288271000 /3650

Email Id : aysetulinoz@ osmaniye.edu.tr 
and GABA treatments ${ }^{10-13}$ as an alternative eco-friendly and natural surface treatment of fresh fruit. In previous reports, it was stated that surface treatments of fresh fruit not only delay physiological disorders but also protect fruit quality longer. The main objective of present study was to investigate postharvest treatment of GABA and OA on sugar, organic acid, total phenolic, anthocyanin and radical scavenging activity of 'Hicaznar' pomegranate fruit arils.

\section{MATERIAL AND METHODS}

Materials: Pomegranate 'Hicaznar' fruits were harvested commercially optimal stage from Mersin region of Turkey. After harvest fruits were transferred laboratory. Pomegranates were washed with clear water, then arils were removed from peel manually. Then arils were immersed external three different concentrations $(0,2.5$ and $5 \mathrm{mM})$ of oxalic acid $(\mathrm{OA})$ and gamma-aminobutyric acid (GABA) for postharvest treatment. For control group distilled water was used. The arils were immersed in solutions for $5 \mathrm{~min}$ at room temperature. After dipping, residuary of solution was removed onto sterilized sieved trays at $20^{\circ} \mathrm{C}$. The arils were transferred to polypropylene bags and stored for 20 days.

\section{METHODS}

Total phenolic, ${ }^{14}$ total anthocyanin,,${ }^{15}$ sugar,,${ }^{16}$ and organic acid contents, ${ }^{17}$ were determined after storage of 0,4 , $8,12,16$ and 20 days. Total antioxidant activity was measured using a free radical DPPH (2,2-diphenyl1-picrylhydrazyl) methanolic solution ${ }^{18}$ SPSS statistical software (version 18.0, Chicago, IL) were used for analysing data. At 5\% level, the significance of differences among means was detected with Duncan test by using one-way ANOVA.

\section{RESULTS \& DISCUSSION}

The predominant organic acids are citric acid and L-ascorbic acid in pomegranate fruit which is one of the most important organic acid that has defence mecanism to biotic and abiotic stress. There are small amounts of malic, succinic, and fumaric acids. Malic acid and succinic acid content was tended to increased in fruits during storage. In our study, L-ascorbic acid content was higher than other organic acids in the pomegranate fruit variety (Table 1). The fumaric acid content did not change significantly during storage trial among treatments. The succinic acid and ascorbic acid content was the highest in oxcalic acid treatment of $2.5 \mathrm{mM}$ concentartion at the end of the storage period. The present findings indicated that L-ascorbic acid was higher in GABA treated fruit compaterd $\mathrm{OA}$ and control arils. The sugar content of pomegranate fruit shows quality of fruit and it varies among cultivars. Fructose, glucose, and total sugar are important for fruit taste. The glucose level was changed between 5.5 to $4 \%$ and fructose was 6.6 to $5 \%$ and total sugar was 12.6 to $15.06 \%$ during storage in all treatments. Pomegranate fruit have higher amount of glucose and fructose than other fruits. The present results were indicated that in general, glucose and sucrose content of fruit slightly decreased at the end of the storage while fructose and sorbitol slightly increased (Table 1). Sorbitol is a sugar alcohol and it was stated that sorbitol level of fruits generally increases by senescence of fruit. ${ }^{19}$ There were no significant differences in TSS level of arils durig storage among treatments. The arils treated with $2.5 \mathrm{mM}$ OA had the highest DPPH scavenging activity during storage. However, GABA treated groups at concentration of 2.5 and $5 \mathrm{mM}$ had the lowest antiradical activity against DPPH. Razavi and Hajiloub $^{20}$ reported that peach fruits treated with $5 \mathrm{mM}$ OA had higher antioxidant capacity than peach which was treated with 1 and $3 \mathrm{mM}$ OA. Huanga et al..$^{21}$ also stated that $\mathrm{OA}$ treatment reduced the injury caused by radical and delayed fruit ripening and senescence. To evaluate effects of antioxidant activity in natural sources are very important and popular in recently. ${ }^{22}$ According to our results, OA showed better antiradical activity than GABA. Pomegranate fruit has natural phytochemical and bioactive compounds which prevent many diseases like depression, cardiovascular diseases and cancer. ${ }^{23-24}$ In addition phenolic compounds also have important to prevent many diseases ${ }^{25-26}$. Total phenolic contents of pomegranate arils were changed significantly during storage. However, there were no significant differences among groups in regard to total phenolic content at the end of the storage. In general, OA treatment at both concentrations had higher total phenolic content and there were no significant differences between concentration of 2.5 and $5 \mathrm{mM}$. TAC of the arils had the highest in GABA treated group compared others at the end of storage.

\section{CONCLUSION}

While the succinic acid and ascorbic acid content was the highest in oxcalic acid treatment of $2.5 \mathrm{mM}$ conconcentration. At the end of the storage period, the present results indicated that L-ascorbic acid was higher in GABA treated fruit than OA and control arils. TSS did not change significantly during storage. OA treatment showed higher radical scavenging and total phenolic 
ஓ

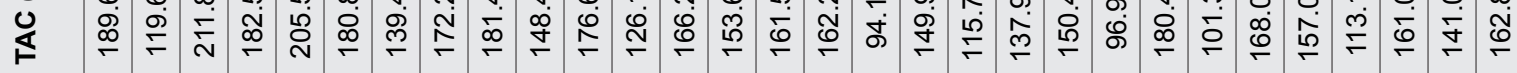

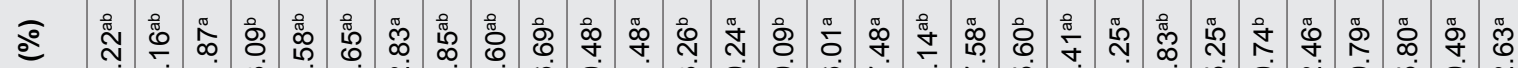

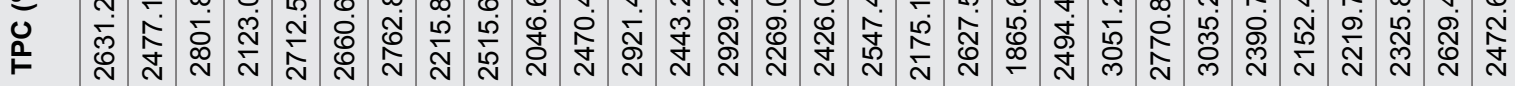

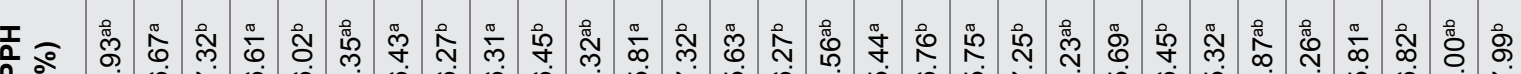

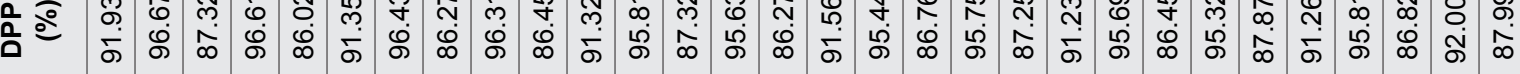
ص

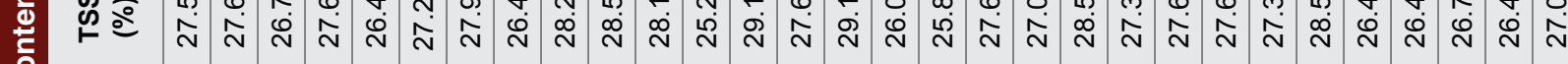
言 跑 㖁 혼

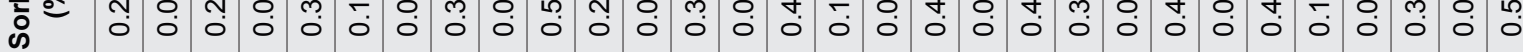

总

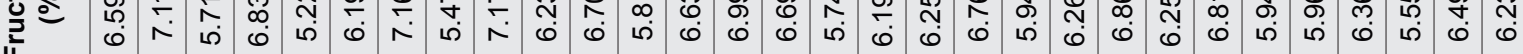

营

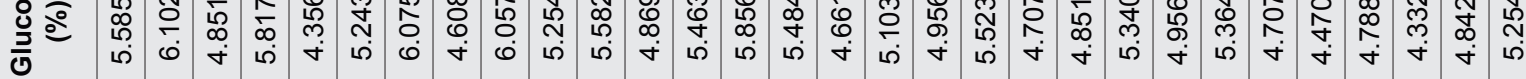
总 U

흔 옹 总

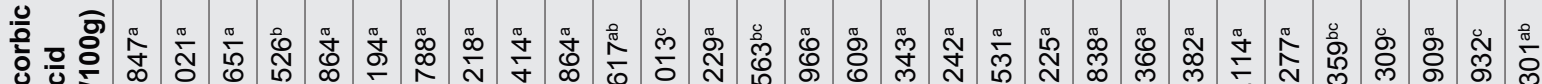

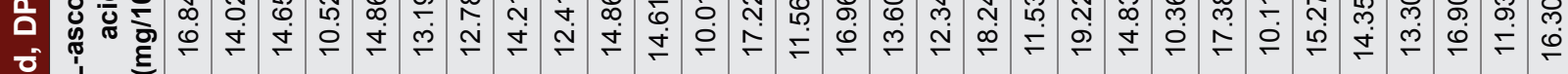

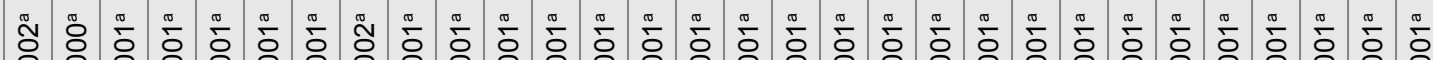
o. 0 i

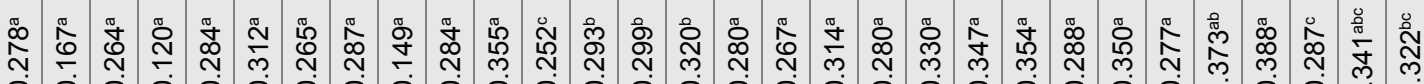

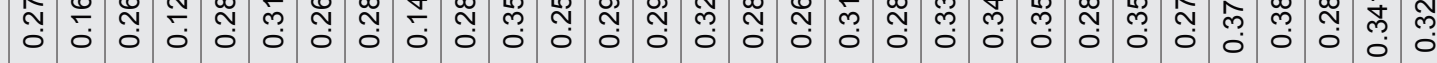

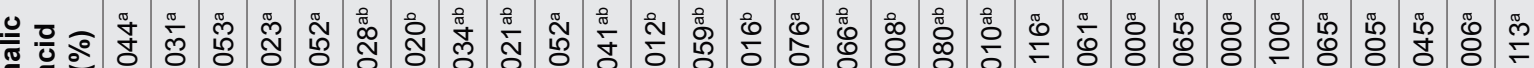
远

\begin{tabular}{|c|c|c|c|c|c|c|c|c|c|c|c|c|c|c|c|c|c|c|}
\hline 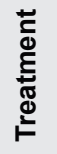 & 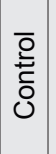 & 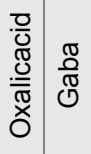 & 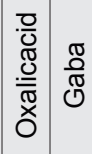 & $\begin{array}{l}\overline{0} \\
\overline{0} \\
0 \\
0 \\
0\end{array}$ & 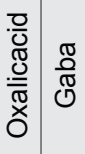 & 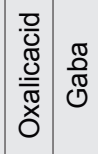 & 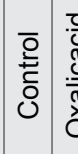 & 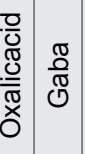 & 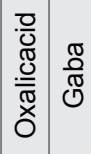 & $\begin{array}{l}\overline{\underline{\partial}} \\
\overline{\underline{\nu}} \\
0 \\
0\end{array}$ & 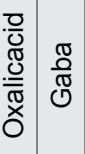 & 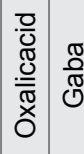 & 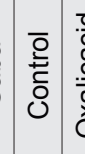 & 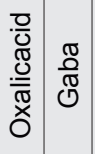 & 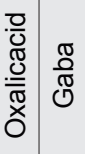 & $\begin{array}{l}\overline{0} \\
\overline{0} \\
0 \\
0 \\
0 \\
0\end{array}$ & 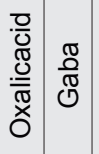 & 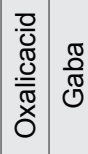 \\
\hline & 0 & $\stackrel{\sim}{\sim}$ & م & 0 & $\stackrel{\sim}{\sim}$ & م & 0 & $\stackrel{\infty}{\sim}$ & مـ & 0 & $\stackrel{n}{\sim}$ & م & 0 & $\stackrel{n}{\sim}$ & ద & 0 & $\stackrel{\infty}{\sim}$ & 1) \\
\hline & & 0 & & & $\checkmark$ & & & $\infty$ & & & $N$ & & & $\stackrel{0}{\square}$ & & & ㄱ & \\
\hline
\end{tabular}


values. It is suggested that further works should be done to understand better the mechanism by which $\mathrm{OA}$ and GABA delay fruit ripening at the molecular level.

\section{ACKNOWLEDGMENTS}

This research was supported by Osmaniye Korkut Ata University Scientific Research Project (OKU-BAP2017-PT3-005 and OKU-BAP-2017-PT3-017, OsmaniyeTurkey). The authors would like to thanks to OKUBAP for providing financial support.

\section{CONFLICT OF INTEREST}

Authors state no conflict of interest

\section{ABBREVIATION USED}

TSS: Total soluble solid; DPPH: DPPH scavenging activity; TPC: Total phenolic content; TAC: Total anthocyanin content.

\section{REFERENCES}

1. Ayhan Z, Eştürk O. Overall quality and shelf life of minimally processed and modified atmosphere packaged "ready to eat" pomegranate arils. J Food Sci. 2009;74(5):399-5.

2. Ojeda GA, Sgroppo SC, Zaritzky NE. Application of edible coatings in minimally processed sweet potatoes (Ipomoea batatas L.) to prevent enzymatic browning. Int J Food Sci Tech. 2014;49(3):876-3

3. Garcia LC, Pereira LM, de Luca Sarantópoulos $\mathrm{CI}$, Hubinger MD. Selection of an edible starch coating for minimally processed strawberry. Food Bioprocess Tech. 2010;3(6):834-2.

4. Yang A, Cao S, Yang Z, Cai Y, Zheng Y. Y-Aminobutyric acid treatment reduces chilling injury and activates the defence response of peach fruit. Food Chem. 2011;129(4):1619-2.

5. Jin P, Zhu H, Wang L, Shan T, Zheng Y. Oxalic acid alleviates chilling injury in peach fruit by regulating energy metabolism and fatty acid contents. Food Chem. 2014;161:87-3.

6. Zhu Y, Yu J, Brecht JK, Jiang T, Zheng X. Pre-harvest application of oxalic acid increases quality and resistance to Penicillium expansum in kiwifruit during postharvest storage. Food Chem. 2016;190:537-3.

7. Öz AT, Kafkas NE, Bozdoğan A. Combined effects of oxalic acid treatment and modified atmosphere packaging on postharvest quality of loquats during storage. Turk J Agric For. 2016;40(3):433-0.
8. Wang Y, Luo Z, Huang X, Yang K, Gao S, Du R. Effect of exogenous $\mathrm{Y}$-aminobutyric acid (GABA) treatment on chilling injury and antioxidant capacity in banana peel. Sci Hortic. 2014;168:132-7.

9. Li P, Yin F, Song L, Zheng X. Alleviation of chilling injury in tomato fruit by exogenous application of oxalic acid. Food Chem. 2016;202:125-2.

10. Sheng L, Shen D, Luo Y, Sun X, Wang J, Luo T, et al. Exogenous $Y$-aminobutyric acid treatment affects citrate and amino acid accumulation to improve fruit quality and storage performance of postharvest citrus fruit. Food Chem. 2017;216:138-5.

11. Romanazzi G, Smilanick JL, Feliziani E, Droby S. Integrated management of postharvest gray mold on fruit crops. Postharvest Biol Technol. 2016;113:69-6.

12. Wang Z, Cao J, Jiang W. Changes in sugar metabolism caused by exogenous oxalic acid related to chilling tolerance of apricot fruit. Postharvest Biol Technol. 2016;114:10-6.

13. Yu C, Zeng L, Sheng K, Chen F, Zhou T, Zheng X, et al. Y-Aminobutyric acid induces resistance against Penicillium expansum by priming of defence responses in pear fruit. Food Chem. 2014;159:29-7.

14. Singleton VL, Rossi JA. Colorimetry of total phenolics with phosphomolybdicphosphotungstic acid reagents. Am J Enol Vitic. 1965;16(3):144-158.

15. Wrolstad RE. Color and pigment analyses in fruit products. Agricultural Experiment Station Bulletin 624 Reprinted May 1993 Corvallis: Oregon State University.

16. Miron DP, Arthur A. Sucrose phosphate synthase, sucrose synthase, and invertase activities in developing fruit of Lycopersicon esculentum Mill. and the sucrose accumulating Lycopersicon hirsutum Humb and Bonpl. Plant Physiol. 1991;95(2):623-7.

17. Bozan B, Tunalier Z, Koşar M, Altıntaş A, Başer KHC. Comparison of ascorbic and citric acid contents in 'Emphasis Type'. In Proc 11. Symp Plant Origin Crude Drugs Ankara 1997.

18. Brand-Williams W, Cuvelier ME, Berset C. Use of a free radical method to evaluate antioxidant activity. LWT-Food Sci Technol.1995;28(1):25-0.

19. Hamauzu Y, Chachin K, Ding CK, Kurooka H. Differences in surface color, flesh firmness, physiological activity, and some components of loquat fruits picked at various stages of maturity. J Jpn Soc Hortic Sci. 1997;65(4):859-9.

20. Razavi F, Hajilou J. Enhancement of postharvest nutritional quality and antioxidant capacity of peach fruits by preharvest oxalic acid treatment. Sci Hortic. 2016;200:95-1.

21. Huang $H$, Jing G, Guo L, Zhang D, Yang B, Duan X, et al. Effect of oxalic acid on ripening attributes of banana fruit during storage. Postharvest Biol Technol. 2013;84:22-7.

22. Lobo V, Patil A, Phatak A, Chandra N. Free radicals, antioxidants and functional foods: Impact on human health. Pharmacogn Rev. 2010;4(8):118-6.

23. Shastry R, Sharma A, Sayeli V, Dinkar US. Screening of Antidepressant Activity of Punica granatum in Mice. Phcog J. 2017;9(1):27-9.

24. Sak K. Cytotoxicity of dietary flavonoids on different human cancer types. Phcog Rev. 2014;8(16):122-46.

25. Gözlekçi S, Saraçoglu O, Onursal E, Özgen M. Total phenolic distribution of juice, peel, and seed extracts of four pomegranate cultivars. Phcog Mag. 2011;26(7):161-4.

26. Zhang XA, Zhang S, Yin Q, Zhang J. Quercetin induces human colon cancer cells apoptosis by inhibiting the nuclear factor-kappa B Pathway. Phcog Mag. 2015;11(42):404-9. 
PICTORIAL ABSTRACT

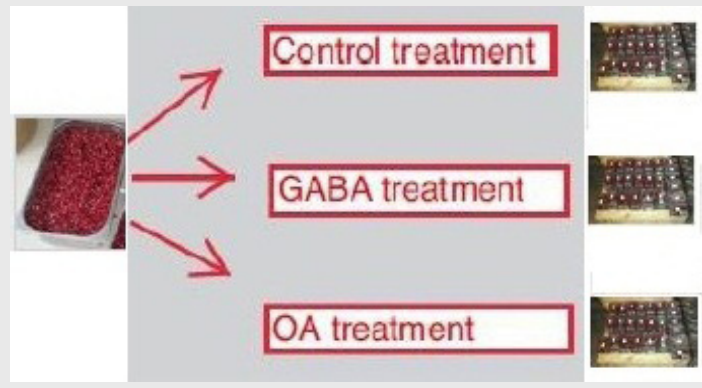

ABOUT AUTHORS

\section{SUMMARY}

- The effects of postharvest treatment of GABA and $\mathrm{OA}$ on phytochemicals, organic acid and sugar content of 'Hicaznar' pomegranate fruit arils were investigated.

- Both OA and GABA treaments have different effects on fruits arils contents during storage.

- It can conculuded that GABA and OA treatments have some positive effects on radical scavenging, TAC level, organic acids and sugar content of pomegranate arils at the end of storage life.

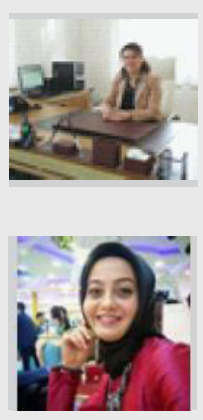

Dr. Ayșe Tülin Öz: is working as Assoc. Prof. Dr at Osmaniye Korkut Ata University and She is head of Dept. Of Food Engineer at Osmaniye Korkut Ata University, her research area is postharvest physiology and she has about 10 years of teaching experience at University.

Șeyma Hiçyllmaz: is Food Engineer and she is master student at Osmaniye Korkut Ata University Food Engineering Dept. in Turkey

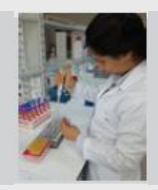

Tuğçe Yarși: is Food Engineer and she is master student at Osmaniye Korkut Ata University, Food Engineering Dept. in Turkey

Cite this article: Öz AT, Hiçyilmaz S, Yarsi T. Effects of the Alternative Postharvest Treatments on 'Hicaznar' Pomegranate Fruit Phytochemicals, Organic Acids and Sugar Content. Indian J of Pharmaceutical Education and Research. 2017;51(3)Suppl:S445-49. 